\title{
Ciência Polar e a Comunicação entre estudantes, educadores e cientistas
}

\begin{tabular}{|c|c|}
\hline $\begin{array}{l}\text { Núbia Déborah Araujo } \\
\text { Caramello }\end{array}$ & $\begin{array}{l}\text { Universidad Autónoma de Barcelona. Departamen- } \\
\text { to do Doutorado em Geografia. Campus de Bella- } \\
\text { terra, Edifici B, Carrer de la Fortuna, s/n, CEP. } \\
08193 \text { Bellaterra, Barcelona, Espanha. } \\
\text { Endereço Atual: Secretaria de Educação do Estado } \\
\text { de Rondônia (SEDUC). R. Corumbiara, 5323. } \\
\text { Centro, Rolim de Moura. RO. CEP: } 78987-000 . \\
\text { E-mail: nubiacaramello@yahoo.com.br }\end{array}$ \\
\hline $\begin{array}{l}\text { Juliana Assunção Ivar } \\
\text { do Sul }\end{array}$ & $\begin{array}{l}\text { Instituto de Oceanografia, Universidade Federal de } \\
\text { Rio Grande (FURG). Av. Itália km 8, Rio Grande, } \\
\text { RS. CEP 96203-900 } \\
\text { E-mail: julianasul@gmail.com }\end{array}$ \\
\hline Juliana Silva Souza & $\begin{array}{l}\text { Universidade Federal do Rio de Janeiro (UFRJ). } \\
\text { Instituto de Bioquímica Médica Leopoldo de Meis. } \\
\text { Mestrado Profissional em Educação, Gestão e } \\
\text { Difusão em Ciências. RJ. } \\
\text { Endereço Atual: UFRJ. Instituto de Biofísica Carlos } \\
\text { Chagas Filho. Av. Carlos Chagas Filho, 373. CEP: } \\
\text { 21941-902. Rio de Janeiro. Rio de Janeiro. } \\
\text { E-mail: julianasouzabiologia@gmail.com }\end{array}$ \\
\hline $\begin{array}{l}\text { Elaine Alves dos San- } \\
\text { tos }\end{array}$ & $\begin{array}{l}\text { Universidade do Estado do Rio de Janeiro } \\
\text { (UERJ). Laboratório de Geocronologia e Isótopos } \\
\text { Radiogênicos (LAGIR). Rua São Francisco Xavier, } \\
\text { 524. Pavilhão João Lyra Filho. BI. F. Sala 4043. } \\
\text { CEP: 20559-900, Maracanã, Rio de Janeiro, RJ } \\
\text { E-mail: elainealves1301@gmail.com }\end{array}$ \\
\hline Roberta da Cruz Piuco & $\begin{array}{l}\text { Colégio La Salle Esteio. Av. Padre Claret, } 1690 . \\
\text { Parque Amador, Esteio, RS. CEP: } 93280-260 \\
\text { E-mail: ropiuco@gmail.com }\end{array}$ \\
\hline $\begin{array}{l}\text { Sandra Freiberger Af- } \\
\text { fonso }\end{array}$ & E-mail: sfreiberger@gmail.com \\
\hline Francyne Elias-Piera & $\begin{array}{l}\text { Division of Polar Ocean Environment, Korea Polar } \\
\text { Research Institute. Pós doutoranda. 26- } \\
\text { Songdomirae-ro, R3-613-1. CEP 21990. Incheon, } \\
\text { Coréia do Sul. } \\
\quad \text { E-mail: francyne.ep@kopri.re.kr }\end{array}$ \\
\hline Moacir Silva & APECS-Brasil \\
\hline
\end{tabular}




\begin{tabular}{ll}
\hline $\begin{array}{l}\text { Luiz Antônio da Costa } \\
\text { Rodrigues }\end{array}$ & $\begin{array}{l}\text { Universidade Federal do Rio de Janeiro. Horto } \\
\text { Botânico-Quinta da Boa Vista s.n. São Cristóvão, } \\
\text { Rio de Janeiro, RJ-Brasil. CEP: 20940040. } \\
\text { E-mail: luyzantonio_@hotmail.com }\end{array}$ \\
\hline $\begin{array}{l}\text { José Carlos Caetano } \\
\text { Xavier }\end{array}$ & $\begin{array}{l}\text { Centro de Ciências do Mar e Ambiente (MARE), } \\
\text { Departamento das Ciências da Vida, Universidade } \\
\text { de Coimbra, 3001-401 Coimbra, Portugal. } \\
\text { E-mail: jccx@cantab.net }\end{array}$ \\
\hline & $\begin{array}{l}\text { Universidade Estadual do Rio Grande do Sul (UE- } \\
\text { RGS). Pró-Reitoria de Pesquisa e Pós-Graduação. }\end{array}$ \\
& $\begin{array}{l}\text { Rua Sete de Setembro, 1156. Centro Histórico. } \\
\text { Porto Alegre. RS. CEP: 90010-191. }\end{array}$ \\
Mestrado Profissional em Educação, Gestão e \\
Difusão em Ciências. Instituto de Bioquímica Médi- \\
ca Leopoldo de Meis. Universidade Federal do Rio \\
de Janeiro (UFRJ)
\end{tabular}

Recebido em: 19 maio 2017. Aceito: 07 jun. 2017.

DOI: http://dx.doi.org/10.21674/2448-0479.32.340-371

\section{Resumo}

A Associação de Pesquisadores e Educadores em Início de Carreira sobre o Mar e os Polos (APECS-Brasil), comitê brasileiro da Association of Polar Early Career Scientists (APECS), vem desenvolvendo, no Brasil, atividades de divulgação da ciência polar de forma direta e contínua, reflexo das ações e projetos desenvolvidos no contexto do Ano Polar Internacional (2007-2009). A APECS-Brasil, no contexto das Semanas Polares Internacionais (SPIs), promove desde 2008 a integração de escolas de todo o Brasil. Nossos objetivos são: incentivar a comunicação, divulgação e compreensão da ciência em sala de aula e em ambientes não formais de educação e; aproximar educadores, cientistas e estudantes da ciência polar, trazendo conhecimentos para o dia-a-dia da sala de aula. A ideia é de preparar o professor, agente direto de construção do conhecimento dentro da 
sala de aula, como disseminador do conhecimento sobre o mar e os polos através da troca de informações entre pesquisadores e professores. Para facilitar a inclusão destas atividades e auxiliar os professores foi desenvolvido um tutorial que apresenta ideias de abordagem da ciência antártica em sala de aula, despertando o interesse dos estudantes pela pesquisa científica e aproximando a ciência da realidade local e possibilitando um diálogo interdisciplinar e multidisciplinar em sala de aula.

Palavras-chave: Pesquisa polar. Multidisciplinaridade. Avanço científico. Educação científica.

\section{Abstract \\ Polar Science and Science Communication among students, educators and scientists}

The Association of Polar Early Career Scientists (APECS-Brazil), a Brazilian committee of the Association of Polar Early Career Scientists (APECS), has been developing polar science divulgation activities in Brazil as a reflection of the actions and projects developed in the context of the International Polar Year (2007-2009). Since 2008, APECS-Brazil has been promoting the integration of schools throughout Brazil within the International Polar Weeks (SPIs). Our objectives are: to encourage communication, dissemination and understanding of science in the classroom and in non-formal education environments; to bring educators, scientists and polar science students together, bringing insights into the everyday classroom. The idea is to prepare the teacher, a direct agent of knowledge construction, as a disseminator of knowledge about the sea and the poles through the exchange of information between researchers and teachers. To facilitate the inclusion of these activities and to assist teachers, we developed a tutorial that presents ideas to introduce 
Antarctic science in the classroom, arousing students' interest in scientific research, bringing science closer to the local reality and enabling an interdisciplinary and multidisciplinary dialogue in classroom.

Keywords: Polar research. Multidisciplinarity. Scientific advance.

Scientific education.

\section{Introdução}

O interesse científico e público relacionado às regiões polares aumentou principalmente devido ao interesse em compreender 0 processo da iminência das mudanças climáticas globais e seus impactos no futuro próximo (HUGHES; CONVEY, 2010), justificando assim o advento do IV Ano Polar Internacional (API) entre os anos de 2007 e 2009. O API é um grande programa científico voltado aos ambientes polares que envolve cientistas de mais de 60 países. Diversos aspectos relacionados a pesquisas nas áreas da física, da biologia, geologia, educação e das ciências sociais são abordados (KRUPNIL et al., 2011). Neste contexto, a divulgação da ciência, principalmente aquela relacionados aos ambientes polares, torna-se um dos importantes pilares dos projetos desenvolvidos no âmbito do API (KAISER et al., 2010; XAVIER et al., 2016).

Escolas brasileiras, seguindo um contexto internacional, devem proporcionar a reflexão sobre mudanças políticas, econômicas, sociais e culturais da sociedade (KRASILCHIK, 2000). Existe, neste sentido, a necessidade em serem incluídas no currículo escolar discussões sobre os ambientes polares que tanto afetam nossa vida cotidiana. Entretanto, - o excesso de informações - produzidas diari- 
amente não permite que a formação dos futuros professores seja completa em todos os aspectos, devendo ser realizada de forma constante e continuada, promovendo a atualização destes (BARCELOS; VILLANI, 2006). Adicionalmente, os livros didáticos, que são auxiliares imediatos da grande maioria dos professores, em geral não contém informações sobre as regiões polares ou, muitas vezes, estas apresentam-se incompletas e pouco atrativas (RODRIGUES et al., 2013a). O agravante é que quando chegam em sala de aula através dos livros didáticos esses se encontram com dados desatualizados, devido ao complexo ciclo de produção-divulgação-inserção da ciência no sistema educacional.

Com base nesse cenário, a Associação de Pesquisadores e Educadores em Início de Carreira sobre o Mar e os Polos (APECSBrasil), comitê brasileiro da Association of Polar Early Career Scientists (APECS), vem desenvolvendo no Brasil atividades de divulgação da ciência polar de forma direta e contínua, reflexo das ações e projetos desenvolvidos no contexto do API. Dentre estas atividades destacam-se as Semanas Polares Internacionais (SPIs) que tem o objetivo de promover a difusão da ciência e dos conhecimentos sobre o mar e os ambientes polares para toda a comunidade, em especial educadores e estudantes dos mais diversos níveis de ensino.

Com o objetivo de construir uma proposta pedagógica, contendo conteúdos contemporâneos para que o conhecimento adquirido seja efetivamente apropriado por alunos e professores, um tutorial contendo orientações detalhadas de atividades e informações sobre os ambientes polares foi desenvolvido. Sendo assim, o presente artigo tem como objetivo descrever o tutorial desenvolvido pela APECS-Brasil, cuja importância está explícita na relevância dos ambientes polares para o planeta e pela necessidade de adequação do tema dentro da sala de aula. O tutorial foi formulado estrategica- 
mente para que o conhecimento adquirido possa ser utilizado por professores dos mais diversos níveis da Educação, inserindo definitivamente a ciência, em especial aquela relacionada aos ambientes polares, para dentro da sala de aula.

\section{Materiais e Métodos}

O texto produzido traz informações gerais sobre os ambientes polares no decorrer do artigo, para que os professores da Educação Básica e outros interessados em divulgação da ciência e/ou ciência polar possam utilizar em sala de aula ou outros ambientes de educação, formal ou não-formal. O Tutorial (Anexo 1) apresenta atividades de acordo com idade / série dos estudantes e também link com sugestões de textos e outras opções de ações associadas a proposta.

\section{A base científica do diálogo polar}

\section{Ecossistemas polares: uma abordagem geral}

As regiões polares são o Ártico, no hemisfério norte, e a Antártica, no hemisfério sul. As duas regiões são localizadas em latitudes elevadas e são ambientes frios marcadamente influenciados pela neve e pelo gelo. Apesar das semelhanças, as duas regiões polares são diferentes em muitos aspectos (CLARKE; HARRIS, 2003).

O Ártico abriga uma população humana nativa que vive em cidades localizadas em latitudes superiores aos $60^{\circ} \mathrm{N}$ (60 graus de 
latitude Norte), algumas situadas dentro do círculo polar (por exemplo, Murmansk, Norilsk e Vorkuta na Rússia e Tromsø na Noruega). Devido à antiga presença do homem na região e a proximidade geográfica com países mais desenvolvidos e com interesses econômicos e políticos na região, o Ártico vem sendo monitorado e estudado há mais tempo e com intensidade maior que a Antártica.

O Ártico, diferente da Antártica, é uma região de mar coberta de gelo. O mar permanece congelado durante a maior parte do ano, principalmente na região central. Durante o inverno setentrional, a banquisa de gelo tem uma espessura de dois a quatro metros e ocupa toda a superfície do oceano Ártico. Já no período de verão, a banquisa se retrai por efeito do aumento de temperatura em um processo natural, que atualmente encontra-se alterado pelas mudanças globais (CLARKE; HARRIS, 2003). Se por um lado a fauna e a população local sofrem com o aumento das áreas livres de gelo durante o verão, por outro lado as empresas de transporte marítimo mundial comemoram a abertura de uma passagem segura através do norte do globo ligando Europa e Ásia.

O nome Antártica significa "oposto de Ártico". A Antártica é o continente mais ao sul do planeta, sendo conhecido como continente dos extremos: é o mais seco, o mais frio, o mais ventoso e o que apresenta maior altitude média. É um ambiente tão desafiador e remoto que não possui população humana permanente. A região Antártica é composta pelo continente e por 26 arquipélagos que se localizam ao redor do continente, nas regiões Subantárticas e no Oceano Austral (ao sul de $60^{\circ}$ de latitude sul). A maioria dessas ilhas não é habitada nem visitada por pesquisadores em atividades científicas. As Montanhas Transantárticas compõem uma cadeia de montanhas que divide o continente nos quadrantes Leste e Oeste. À Leste estende-se o platô Antártico que possui um vasto manto de Rev. Elet. Cient. UERGS, , v. 3, n. 2, p.340-371, 2017 
gelo recobrindo o substrato rochoso, uma região tão seca quanto o deserto do Saara (SETZER et al., 2004). À Oeste forma-se a Península Antártica que se estende em direção ao sul da América do Sul. É na Península Antártica que se desenvolvem a maioria das pesquisas brasileiras na Antártica.

$\mathrm{Na}$ Antártica encontra-se aproximadamente $90 \%$ do gelo e $70 \%$ da água doce do planeta (SIMÕES et al., 2011). A água que ocorre na forma sólida, forma um manto de gelo cuja espessura pode chegar a quatro mil metros. É devido a esta vasta superfície congelada que a Antártica atua como principal sorvedouro do calor terrestre, tendo função preponderante no sistema climático terrestre (FRANCELINO et al., 2004).

Nas margens do continente e nas ilhas Antárticas e Subantárticas observa-se um clima mais úmido e ameno quando comparado ao interior do continente devido à influência marítima (FRANCELINO et al., 2004). Este clima mais moderado é mais propício ao desenvolvimento de ecossistemas com maior diversidade, como, por exemplo, as comunidades vegetais resultantes da associação entre musgos, líquens e gramíneas que se desenvolvem nas áreas livres de gelo (FRANCELINO et al., 2004). Essas áreas terrestres também são utilizadas como abrigo e/ou áreas de reprodução para uma grande variedade de espécies de aves e mamíferos marinhos. Porém, é no Oceano Antártico que se encontram a maior riqueza e diversidade biológica do planeta (CLARKE; JOHNSTON, 2003; HUGHES; CONVEY, 2010). A base de toda a teia trófica da Antártica está no oceano: o fitoplâncton serve de alimento para o zooplâncton, entre eles o krill Euphausia superba, uma espécie de crustáceo que constitui o principal alimento de predadores secundários, tais como: peixes, aves e mamíferos marinhos (XAVIER; PECK, 2015). 


\section{Delineamento histórico: do desbravamento do polo sul ao tratado antártico}

Os ambientes polares, em especial a Antártica, devido ao seu isolamento geográfico, extensão, diversidade, registro geológico, entre outros, tem despertado o interesse de exploradores, historiadores, pesquisadores, estudantes, aventureiros e curiosos por séculos (PROVENCHER et al., 2011). Existem dezenas de relatos daqueles que primeiro se aventuraram rumo aos mares austrais, enfrentando a travessia da difícil Passagem de Drake para chegar ao extremo sul do planeta. Os primeiros documentos que registram a existência de terras na latitude de $52^{\circ} \mathrm{S}$ são creditados a Américo Vespúcio e datados do século XVI (CAPDEVILA; MONTALBÁN, 2013). Já em 1772, James Cook chegou às Ilhas Subantárticas Geórgias do Sul (53오) e declarou que não haviam terras mais ao sul, o que desestimulou temporariamente a busca por um possível continente. Foi somente em 1820 que Nathaniel Palmer conseguiu avistar o Continente Antártico pela primeira vez, seguido pelo russo Fabian Bellingshausen e pelo comandante inglês Edward Bransfield que também confirmaram o avistamento da então chamada Terra Australis Incognita. O primeiro a realmente pisar no continente Antártico foi o caçador de focas e comandante do Navio Cecília John Davis em 1821 (Baia de Hughes, Península Antártica) (HALZEN, 2012). O Comandante russo Bellingshausen também descobriu novas terras a leste da Península Antártica no Mar que hoje leva seu nome (FRANCO, 2014).

A exploração e a conquista do continente se iniciam a partir de 1985 quando Henrik Bull e Carsten Borchgrevink aportaram no Continente Antártico. A partir de então se inicia a caça às baleias, atividade que demandou a instalação de dezenas de estações de Rev. Elet. Cient. UERGS, , v. 3, n. 2, p.340-371, 2017 
apoio em terra e que, após a proibição da caça, passaram a ser utilizadas como bases e estações de pesquisa. A conquista do Polo Sul ocorreu em 14 de dezembro de 1911, quando cinco noruegueses, liderados por Roald Amundsen, estabeleceram um acampamento na latitude 90ㅇ (CAPDEVILA; MONTALBÁN, 2013).

$O$ desenvolvimento da ciência e os grandes investimentos em pesquisas observados a partir do fim da segunda guerra mundial, beneficiaram diversas áreas científicas, em particular a geofísica, a geoquímica e, de um modo geral, as ciências da terra e do espaço. Tornou-se evidente que o estudo dos sistemas terrestres era necessariamente transversal em relação às disciplinas clássicas da física, química, geologia e biologia, e requeria um forte esforço de cooperação interdisciplinar baseado em definições e metodologias bem estabelecidas e consensuais. Os estudos climáticos realizados a partir da década de 1960 permitiram a concepção de um sistema climático composto por vários subsistemas (atmosfera, hidrosfera, criosfera, biosfera e litosfera) em interação mútua, demandando assim estudos de caráter multidisciplinar. Neste contexto, motivados por estas inovações e sob o clima de cooperação internacional reinante após a criação da Organização das Nações Unidas (ONU), um grupo de cientistas renomados propôs a realização do 1ำ Ano Geofísico Internacional (AGI) entre 1957 e 1958. A proposta teve acolhimento favorável por parte dos Estados Unidos da América (EUA), da União Soviética e dos respectivos aliados que a consideraram uma boa oportunidade para fomentar a cooperação entre diferentes países, especialmente na coleta de dados geofísicos em escala global.

As realizações do 1ำ AGI enfatizaram a importância da Antártica para estudos nas áreas de meteorologia, astronomia, geomagnetismo e história natural e deram início às negociações culmi- 
nadas em 1 de dezembro de 1959, quando as 12 nações que reivindicavam território no Continente chegaram a um acordo e ratificaram, na Cidade de Washington, EUA, o Tratado da Antártica, que entrou em vigor em junho de 1961 (PROANTAR, 2001; HALZEN, 2012).

Com a assinatura do Tratado da Antártica, este continente passou a ser protegido devido às suas características únicas, sendo permitidas apenas pesquisas e observações científicas, deixando em suspenso as reivindicações territoriais referentes a toda a área ao sul do paralelo de $60^{\circ} \mathrm{S}$. Mais recentemente, em 1991, foi criado o Protocolo de Proteção Ambiental ou Protocolo de Madrid (ratificado na cidade de Madrid, Espanha), com o objetivo de prevenir a contaminação do ambiente Antártico garantindo assim sua preservação. Cada nação signatária do Tratado da Antártica que conduz atividades de pesquisa na Antártica deve planejar suas ações de modo a minimizar possíveis impactos no ecossistema antártico e em seus ambientes associados (HUGHES; CONVEY, 2010).

\section{A base metodológica do diálogo polar}

\section{O conhecimento sobre a Antártica e os desdobra- mentos na sociedade e na escola}

O conhecimento científico especializado, incluindo o conhecimento sobre as regiões polares, muitas vezes distancia a ciência e a sociedade. Levantando-se assim uma ampla discussão sobre a necessidade de alfabetização científica para possibilitar que o público em geral se aposse do conhecimento científico (KRASILCHIK, 2000). No âmbito das ciências ambientais, a apropriação do conhe- 
cimento científico é importante, pois permite que exista uma reflexão sobre as questões ambientais e suas inter-relações no espaço e no tempo (BOADA; SAURİ, 2002).

É indiscutível que existe uma forte ligação entre o letramento científico, o desenvolvimento científico e a sustentabilidade (PROVENCHER et al., 2011). No Brasil são comuns os currículos de ciências estarem demasiadamente centrados em conteúdos conceituais em detrimento aos conteúdos processuais, tendo como referência a lógica interna da própria ciência. Muitas vezes, a totalidade da formação que a construção científica exige é posta em segundo plano (KRASILCHIK, 2000; ACEVEDO et al., 2005). Esta centralização em conteúdos também acaba deixando de lado processos importantes para o desenvolvimento da relação entre o indivíduo e ambiente, tornando o conhecimento formal/curricular obsoleto.

Neste contexto, os ambientes polares trazem uma grande riqueza de informações, podendo ser abordadas de forma interdisciplinar e em diferentes níveis de ensino. As questões mais frequentemente levantadas são o aquecimento global e as mudanças climáticas porém, o impacto na biosfera pode ser abordado nos contextos físico, biológico e social (SOUZA, 2016). São opções para inserção no currículo, por exemplo, a vida dos primeiros exploradores ou cientistas contemporâneos dos ambientes polares; a diferença entre as cadeias alimentares em altas e baixas latitudes; estratégias dos peixes e outros animais marinhos como forma de adaptação ao frio; curiosidades sobre os pinguins, as aves símbolo da Antártica, entre outras. As oportunidades para um aprendizado empolgante e significativo são inúmeras.

Ainda assim, a abordagem de temas relacionados aos polos e aos mares em sala de aula se configura como um desafio que, sob um olhar crítico, pode compor uma realidade paradigmática. Consi- 
derando a ausência da abordagem e divulgação de tais temas nos cursos de formação de professores bem como nos livros utilizados pelos professores da educação básica, é possível entender a realidade enfrentada pelo docente ao deparar-se com novos conteúdos (RODRIGUES et al., 2014).

Uma abordagem inicial realizada em 14 livros didáticos do ensino fundamental revelou a ocorrência do tema "Antártica" em todos os livros analisados (Tabela 1). Entretanto, o uso de imagens e gráficos foi frequentemente feito em desacordo com a realidade e pode contribuir para a construção de conceitos e interpretações inadequados pelos alunos (RODRIGUES et al., 2013). Neste aspecto, podemos usar um exemplo recorrente: o uso da imagem do globo terrestre - em projeção plana - não permite o estabelecimento de uma conexão entre a imagem e o dado real. Amplamente adotada em livros didáticos esta projeção possui caráter convencional, permitindo a promoção de uma visão reducionista e consequentemente distorcida sobre o Continente Antártico.

Ainda segundo Rodrigues et al. (2014), o fato de não haver uma abordagem adequada subutiliza imagens e assuntos relativos aos temas polares, o que dificulta a inclusão definitiva do tema junto aos conteúdos básicos ofertados em sala de aula. Assim, o distanciamento entre a ciência e a sociedade encontra-se mais uma vez presente, muitas vezes estimulado pela falta de acesso ao conhecimento por parte dos professores. Macedo (2004) relata ainda a reprodução de conhecimentos inalterados nos livros didáticos ao longo de várias décadas, restringindo reformulações teóricas, atualizações e revisões do projeto gráfico e qualidade da matéria física para confecção dos mesmos. 
Tabela 1 - Abordagem do Tema "Antártica" em livros didáticos $(\mathrm{N}=14)$ do Ensino Fundamental adotados por escolas públicas e privadas da região metropolitana do Município do Rio de Janeiro.

\begin{tabular}{l|l|l|}
\hline \multicolumn{1}{c|}{ Abordagem } & \multicolumn{1}{c}{ Sim } & Não \\
\hline $\begin{array}{l}\text { Aborda ou valoriza iniciativas brasileiras na Ciência Polar? } \\
\text { Aborda a importância da Antártica para o clima e ecologia da } \\
\text { Terra? }\end{array}$ & - & 14 \\
\hline Utiliza os polos como exemplos de extremos climáticos? & 11 & 03 \\
\hline A obra apresenta capítulo específico sobre o tema? & - & 14 \\
\hline O tema é abordado em outros capítulos? & 11 & 03 \\
\hline Apresenta imagem do Continente Antártico? & 11 & 03 \\
\hline
\end{tabular}

Fonte: Adaptado de Rodrigues et al. 2013a, 2014.

A ausência de informações sobre o tema "Antártica" durante o período de formação escolar fica claramente apresentado na Figura 1. A maioria dos estudantes entrevistados tem informações sobre o Continente Antártico majoritariamente por meio de notícias, documentários e filmes, mas poucos recebem informações na escola. . Por meio de questionários aplicados por pesquisadores do Laboratório de Radioecologia e Mudanças Globais da Universidade do Estado do Rio de Janeiro (UERJ) para alunos de escolas municipais, pode-se observar que a maioria encontra informações sobre as regiões polares em fontes de informação extracurriculares, quase sempre vinculadas à mídia e a internet, e não dentro da sala de aula (RODRIGUES et al., 2013b). 


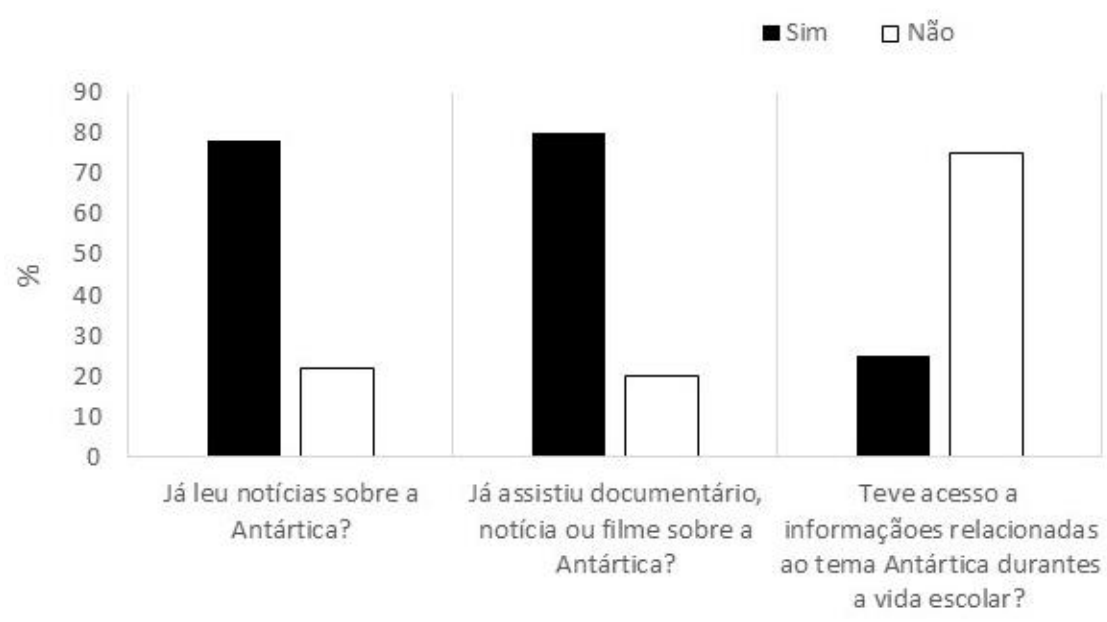

Figura 1 - Acesso a informações sobre o tema "Antártica" por alunos do Ensino Fundamental $(n=102)$ em três escolas municipais da região metropolitana do Rio de Janeiro. Fonte: Adaptado de Rodrigues et al. (2014).

A inclusão de temas relacionados aos polos e aos mares no currículo descrito como intercultural por Libâneo (2003) pode impactar a consciência crítica do aluno e permitir a análise dos conhecimentos elaborados não só dentro da sala de aula, mas em diversos aspectos da vida cotidiana. Tal abordagem permite a ampliação da discussão sobre a importância do Continente Antártico para, por exemplo, o sistema climático-ambiental do planeta e na promoção do pensamento crítico e científico dos estudantes. Tais processos, no entanto, podem ser ineficazes quando realizados de maneira descontínua e isolados sendo extremamente necessária a sistematização da informação, como, por exemplo, por meio de tutoriais.

O tutorial apresentado neste artigo, assim como outras fontes de base teórica e prática sobre a Antártica, pode servir ao docente como instrumento para inserção da Ciência Polar nas salas de aula 
em todos os níveis de ensino, até que esta seja definitivamente integrada ao currículo escolar e de forma adequada no livro didático.

\section{A APECS - Brasil e as Semanas Polares Internacio- nais (SPIs)}

A APECS é uma organização internacional e transdisciplinar dedicada à formação de novos líderes em ciência e educação sobre o mar e os polos. Sua origem ocorreu durante as discussões do API devido à necessidade de formação contínua de novos pesquisadores e educadores interessados nas regiões polares (PROVENCHER et al., 2011). A APECS tem como principal objetivo promover o desenvolvimento de redes de pesquisa e campanhas de comunicação e divulgação da ciência, envolvendo jovens cientistas em atividades de pesquisa, comunicação e educação (www.apecs.is).

A APECS-Brasil é o comitê nacional desta Associação que foi estabelecido em 2008 sob os mesmos princípios da APECS internacional (IVAR DO SUL et al., 2011; www.apecsbrasil.com). Com mais de 2 mil associados, a APECS-Brasil tem participação de estudantes dos diversos níveis de ensino, desde a Educação Básica até a Pósgraduação. São alunos da Educação Básica, pesquisadores em início de carreira e pós-doutores, membros recentes de corpos docentes, professores dos diversos níveis de ensino, mentores seniores e pessoas com interesse nos ambientes marinhos, nas regiões polares, criosfera e regiões andinas. Sendo também a ciência polar utilizada como diálogo de reflexão ambiental de outros ecossistemas, como o projeto desenvolvido na Escola Lira, no Estado de Rondônia - Brasil com o título "Amazônia vai ao Ártico e ao Antártico: um olhar do local para o Global” (CARAMELLO et al, 2013), bus- 
cando a partir da ciência polar estimular novas posturas ambientais no espaço vividos dos estudantes envolvidos na proposta. Para que os objetivos da APECS-Brasil sejam cumpridos, são desenvolvidas, entre outras atividades, propostas pedagógicas para educação formal e informal para promover a discussão da ciência polar por estudantes, educadores e pesquisadores, integrando os diferentes saberes. As SPIs foram criadas para celebrar os Equinócios, representados por um dia com exatamente 12 horas de luz em qualquer parte da Terra, e que marcam o início da primavera no hemisfério norte em março, e início do outono no hemisfério sul em setembro, e viceversa.

As SPIs tiveram início em março de 2012 e desde então são uma importante oportunidade de diálogo entre cientistas, educadores, alunos e a comunidade geral (www.polartrec.com/collections/international-polar-week). Comitês nacionais da APECS utilizam o material disponível do site da APECS internacional ou realizam atividades próprias de acordo com a realidade de cada país.

No Brasil, objetivos complementares das SPIs são despertar o interesse de estudantes, educadores e da comunidade em geral para os ecossistemas marinhos e polares e, principalmente, fazer com que a população conheça a importância, a relevância e as oportunidades da pesquisa como um todo no país. Pesquisadores em início de carreira e sêniores participam ministrando palestras e desenvolvendo nas escolas atividades práticas de difusão e popularização da ciência polar, que permitem a troca de ideias e frequentemente marcam o estabelecimento de relações mais estreitas que geram outras novas oportunidades para divulgação da ciência. Muitas vezes estas atividades ultrapassam as fronteiras físicas do terri- 
tório brasileiro e atingem estudantes de língua portuguesa em diversas partes do mundo.

A APECS-Brasil realizou 12 SPIs entre 2012 e 2015. Adicionalmente, foram realizadas mais de 110 palestras (presenciais e à distância), envolvendo cerca de 100 escolas em todas as regiões da federação, que contaram com a colaboração de dezenas de educadores do ensino fundamental e médio, além de pesquisadores em início de carreira de todo o país. Todas estas atividades estão registradas nos informativos semestrais publicados pela APECS-Brasil que se encontram disponíveis na forma digital em www.apecsbrasil.com.br/informativos, nas páginas virtuais da APECS-Brasil na internet, na imprensa escrita e em diversos órgãos apoiadores destas ações como a APECS internacional. Indicativos numéricos apontam que milhares de pessoas de todos os níveis de ensino e espalhadas em todo o território nacional receberam informações referentes aos ambientes marinhos e polares durante a realização destes eventos.

Dentre as atividades mais recentes vinculadas às SPIs, podese destacar a realização do I Workshop de Desenvolvimento de Carreira (WDC) da APECS-Brasil (Universidade Federal do Rio de Janeiro, Rio de Janeiro, setembro de 2013), quando mais de $10 \mathrm{mil}$ estudantes de todo o país puderam participar das palestras e workshops em tempo real por meio de web conferências. Na mesma época foi realizado o I Seminário Polar na Amazônia (SEDUC/Escola Lira - Rondônia), realizado no anfiteatro municipal com a participação de 250 estudantes e professores do ensino fundamental e médio, além de pesquisadores polares de Portugal, Rio de Janeiro e São Paulo que participaram através de videoconferência. No ano seguinte, durante a XII SPI e II WDC (realizada no Colégio Maria Auxiliadora em Canoas, Rio Grande do Sul, setembro de 
2014), mais de 700 estudantes da educação básica e ensino superior participaram presencialmente de palestras e atividades propostas por 45 educadores e 16 pesquisadores do Brasil, Portugal, Inglaterra e Estados Unidos. Novamente mais de 40 mil estudantes de 30 escolas em todas as regiões da federação participaram, também em tempo real através das web conferências, das atividades e palestras ministradas.

\section{O tutorial como forma de apropriação da informação}

Em 2012, o Núcleo de Educação da APECS-Brasil elaborou um tutorial reunindo sugestões de atividades para serem utilizadas pelos professores durantes as SPIs. O tutorial (Anexo 1) inclui atividades que estão em consonância com o currículo escolar brasileiro, numa tentativa de contribuir com as dinâmicas de ensino vigentes, além de superar a defasagem de conteúdos relacionados aos ambientes polares observada nos livros didáticos da educação básica.

As atividades propostas no tutorial possuem um arcabouço teórico derivado do pensamento freiriano, em que temas geradores relacionados ao ambiente local estimulam o interesse pelo processo de aprendizagem, e pelo pensamento piagetiano, sendo consideradas as fases pelas quais o aluno passa ao longo da busca pelo conhecimento. São estas fases o estágio sensomotor (desde o nascimento até os 18 meses de vida), os estágios pré-operacionais (de 18 meses até 7 anos) e concreto operacional (dos 7 aos 11 anos), e finalmente o estágio formal operacional (dos 11 aos 15 anos) (KRASILCHIK, 2000). As atividades do tutorial preconizam o construtivismo, contribuindo para que a escola seja efetivamente um locus de conhecimento. Porém pode ser utilizado por escolas de diferentes 
linhas pedagógicas. Através da realização das atividades propostas no tutorial espera-se fundamentar e ampliar o conhecimento relativo aos ambientes polares, associando a sua importância frente à questão das mudanças climáticas globais e à necessidade de preservação do meio ambiente não só na Antártica ou no Ártico, mas em todos os ecossistemas terrestres e marinhos. Os professores, neste contexto, atuam como agentes divulgadores das Ciências da Vida, das Ciências da Terra e da Educação Ambiental, visto que a sociedade aspira por esse conhecimento.

O Tutorial (Anexo 1) foi desenvolvido para que professores e educadores pudessem adotar uma sequência lógica no desenvolvimento das ações relacionadas a construção do conhecimento sobre os ambientes polares. Em um primeiro momento solicita-se que o proponente da atividade investigue o grau de conhecimento dos seus alunos. Essa investigação pode ser feita, por exemplo, através de desenhos, no caso de crianças menores de 6 anos; questões gerais sobre os ambientes polares, que poderão ser aplicadas por turma, por grupos ou de forma individual, ou ainda através de redações, no caso de alunos com mais de 16 anos. As atividades também são propostas de acordo com a idade/fase dos estudantes envolvidos. O aprofundamento do conhecimento é proposto por meio de filmes, vídeos, leitura de textos e outras atividades. Para exemplificar são propostas as exibições dos filmes "Procurando Nemo" e "Marcha dos Pinguins"; textos sobre a Antártica que foram publicados nas revistas Ciência Hoje e Ciência Hoje das Crianças, importantes veículos de divulgação da ciência no Brasil; além de entrevistas via Skype com cientistas brasileiros que desenvolvem pesquisas marinhas e polares. Para finalizar, o tutorial indica ações de socialização para estimular a fixação do conhecimento obtido. Entre elas sugere-se que alunos em turmas mais adiantadas apresentem ativi- 
dades ou palestras para os alunos mais jovens. São sugeridas atividades faladas e escritas para contemplar as diversas habilidades dos alunos, promovendo assim ações inclusivas que atendam a maior parte dos alunos em sala de aula.

De acordo com Sulaiman (2011), a sociedade anseia pela partilha do saber da ciência e da tecnologia, em especial nas questões relativas à melhoria da qualidade de vida, do ambiente e da saúde, para assim atingir a sua sustentabilidade. Portanto, além do caráter informativo, a divulgação científica apresenta importante função educativa na formação da opinião pública qualificada (SULAIMAN, 2011). É cada vez mais importante que essa formação seja iniciada durante a educação básica e, de forma continuada, durante toda a vida escolar dos alunos.

Existe um amplo consenso sobre a necessidade da alfabetização científica que permita preparar cidadãos com poder sobre a tomada de decisões quando na fase adulta (PRAIA; GIL-PÉREZ; VILCHES, 2007). O uso de quaisquer ferramentas, desde que aplicadas corretamente, que extrapolem o previsto no currículo formal pode promover novas interações trazendo conhecimentos significativos para os alunos (AB'SABER, 1993; GÓMEZ, 2001). Neste sentido, a aproximação entre a ciência polar e os estudantes pode ser extremamente motivadora tanto para professores quanto para os alunos. Muitas vezes este conhecimento atinge outras esferas da comunidade escolar tomando como exemplos pais dos alunos ou os filhos dos professores, passando a fazer parte do conhecimento de todos vinculados direta ou indiretamente no diálogo polar. 


\section{Considerações finais}

Nos últimos anos, com o apoio da APECS (www.apecs.is) e APECS-Brasil (www.apecsbrasil.com), muitos pesquisadores vêm aderindo à difusão, divulgação e popularização da ciência como parte inerente do seu trabalho, dedicando parte do seu tempo para esta atividade. Todas as atividades que integram cientistas, educadores e alunos são essenciais para que a ações de apoio e incentivo a ciência no Brasil, como financiamentos, bolsas de estudos, auxílios a participação em eventos internacionais e estímulo para a produção de material didático ganhem força e significado. Os resultados se refletem em todos os atores envolvidos e, possivelmente, vão muito mais além. Professores e alunos aumentam seu conhecimento e interesse na ciência; a distância entre ciência e sociedade diminui e torna-se parte integrante da cultura humana, passando a fazer parte dos interesses e aspirações de toda sociedade. Cientistas aperfeiçoam sua habilidade de comunicação e ensino e podem dialogar com o público externo e a academia de forma clara e objetiva.

O tutorial, quando aplicado por professores nos mais diversos níveis de ensino, mostrou-se uma ferramenta poderosa na apropriação do conhecimento por parte dos alunos e, principalmente, um instrumento acessível por parte dos próprios professores que buscam a inserção de diferentes tipos de conhecimento em suas aulas.

O tutorial pode e deve ser utilizado nos mais diversos níveis da Educação objetivando-se, entretanto, a inserção definitiva da ciência, em especial a ciência polar, para dentro da sala de aula. Como consequência dessa ação, o próximo passo é a inserção da ciência de forma integrada, continuada e com a qualidade almejada pelos professores para dentro dos livros didáticos. 


\section{Agradecimentos}

Agradecemos a Franciele Guerra Gagliano pelo apoio na revisão das normas e modelo para submissão na revista. Agradecemos aos dois revisores anônimos pela agilidade na revisão e pelas considerações apontadas. ESC teve apoio do CNPq (processo 405975/2013-9) e da FAPERJ (processo E-26/111.840/2013) durante a elaboração deste artigo. FEP agradece pelo apoio financeiro do Korean Polar Research Institute.

\section{Referências}

AB'SABER, A. Universidade brasileira na (re)construção da educação ambiental. Educação Brasileira, Brasília, v. 15, n. 31, p. 10715, 1993.

ACEVEDO, J. A. et al. La naturaleza de la ciencia y la educación científica para la participación ciudadana: una revisión crítica. Revista Eureka sobre Enseñanza y Divulgación de las Ciencias, Cádiz, v. 2, n. 2, p. 121-140, 2005.

AMAZÔNIA em Clima Polar: Semanas Polares Internacionais e o I Seminário Polar Internacional da Amazônia. In: XX SIMPÓsıO BRASILEIRO SOBRE PESQUISA ANTÁRTICA, 2013, São Paulo. XX Simpósio Brasileiro sobre Pesquisa Antártica. São Paulo, 2013. p. 49-50.

ANALYSIS approach the theme "Antarctica" in the basic education textbooks. In: ENCONTRO NACIONAL DE ENSINO DE CIÊNCIAS DA SAÚDE E DO AMBIENTE, 4., 2014. Anais... Niterói: UFF, 2014. 
BARCELOS, N.N.S.; VILLANI, A. Troca entre universidade e escola na formação docente: uma experiência de formação inicial e continuada. Ciência \& Educação, Bauru, v. 12, n. 1, p. 73-97, 2006. BOADA, M.; SAURÍ, D. El cambio global. Barcelona: Editora Rubens, 2002.

CLARKE, A.; HARRIS, C. Polar marine ecosystems: major threats and future change. Environmental Conservation, Cambridge, v. 30, n. 1, p. 1-25, 2003.

CLARKE, A.; JOHNSTON, N. Antarctic marine benthic diversity. Oceanography and Marine Biology: an Annual Review, Londres, v. 41, p. 47-114, 2003.

CAPDEVILA, R.; MONTALBÁN, C. Los puertos del Plata en la ruta antártica durante la "etapa heroica" In: WÖPPKE, Consuelo León; FERNÁNDEZ, Maurício Jara (Eds). Esbozando la historia antártica latinoamericana: encuentros de historiadores antárticos latinoamericanos, Viña del Mar, 2013. p. 129-150.

FRANCELINO, M. R. et al. 2004. Geoformas da Península Keller, Antártica Marítima: subsídios ao monitoramento ambiental. In: SCHAEFER, C. E.; FRANCELINO, M. R.; SIMAS, F. N. B.; ALBUQUERQUE FILHO, M. R. (Eds). Ecossistemas costeiros e monitoramento ambiental da Antártica Marítima - Baía do Almirantado, Ilha Rei George. Viçosa, 2004. p.15-25.

FRANCO, J. Uma introdução à geopolítica das regiões polares. Revista de Geopolítica, Natal, v. 5, n.2, p. 50-66, 2014.

GÓMEZ, A. L. P. A cultura escolar na sociedade neoliberal. Porto Alegre: Artmed, 2001. 
HALZEN, F. Deep-frozen science. Nature, Londres, v. 483, p. $272-$ 273, 2012.

HUGHES, K.; CONVEY, P. The protection of Antarctic terrestrial ecosystems from inter- and intra-continental transfer of nonindigenous species by human activities: A review of current systems and practices. Global Environmental Change, Guildford, v. 20, p. 96-112, 2010.

IVAR DO SUL, J. A. et al. Crossing the Drake Passage: from Brazil to Antarctica with the association of polar early career scientists (APECS-Brazil), Oecologia Australis, Rio de Janeiro, v. 15, n. 1, p. 177-181, 2011.

KAISER, B.; ZICUS, S.; ALLEN, B. Polar Science and Global Climate: An International Resource for Education \& Outreach. Pearson Custom Publishing, Essex, UK, 2010.

KRASILCHIK, M. Reformas e realidade: o caso do ensino das ciências. São Paulo em Perspectiva, v. 14, n.1, p. 85-93, 2000.

KRUPNIK, I. et al. Understanding earth's polar challenges : International Polar Year 2007-2008, Vol no. 1. University of the Arctic, Rovaniemi, Finland/CCI Press, 2011.

LIBÂNEO, J. C. Adeus professor, adeus professora? Novas exigências educacionais e profissão docente. 7. ed. São Paulo: Cortez, 2003. 
MACEDO, E. A imagem da ciência: folheando um livro didático. Educação \& Sociedade, São Paulo, v. 25, n. 86, p. 15-16, 2004.

O TEMA "Antártica" no currículo formal do ensino fundamental: uma abordagem para o ensino de ciências. In: SIMPÓSIO BRASILEIRO SOBRE PESQUISA ANTÁRTICA, 20., 2013. Anais... São Paulo: CPA/USP, 2013a.

PERCEPÇÃO de alunos do ensino fundamental em escolas públicas no RJ sobre o tema "Antártica": perspectivas e potencialidade interdisciplinar. In: ENCONTRO NACIONAL DE POPULARIZAÇÃO DA CIÊNCIA, TECNOLOGIA E INOVAÇÃO, 2., 2013. Anais... Niterói: NuDCEN/UFF, 2013b.

PRAIA, J.; GIL- PÉREZ, D.; VILCHES, A. O papel da natureza da ciência na educação para a cidadania. Ciência \& Educação, Bauru, v. 13, n. 2, p. 141-156, 2007.

PROANTAR. Tratado da Antártica e protocolo de Madri. Brasília: Subsecretaria para o Programa Antártico Brasileiro, 2001.

PROVENCHER, J. et al. Polar research education, outreach and communication during the fourth IPY: how the 2007-2008 International Polar Year has contributed to the future of education, outreach and communication. Paris: International Council for Science, 2011.

SETZER, A. et al. Regime climático na Baía do Almirantado: relações com o ecossistema terrestre. In: SCHAEFER, Carlos Eduardo; FRANCELINO, Márcio Rocha; SIMAS, Felipe Nogueira Bello; AL- 
BUQUERQUE FILHO, Manoel Ricardo (Org.). Ecossistemas costeiros e monitoramento ambiental da Antártica marítima: Baía do Almirantado, Ilha Rei George, Viçosa, 2004. p. 47-58.

SIMÕES, J. C. et al. Antártica e as Mudanças Globais. São Paulo: Blucher, 2011. v. 9. 169p

SULAIMAN, S. N. Educação ambiental, sustentabilidade e ciência: o papel da mídia na difusão de conhecimentos científicos. Ciência \& Educação, Bauru, v. 17, n. 3, p. 645-662, 2011.

XAVIER, J.C et al. Education on Biodiversity in the Polar Regions. In: CASTRO, P.; AZEITEIRO, U.M.; BACELAR-NICOLAU, P.; FILHO, W.L.; AZUL, A. M. (Eds) Biodiversity and education for sustainable development. Springer International Publishing, Switzerland, 2016.

XAVIER, J.C.; PECK, L.S. Life Beyond the Ice. In: LIGGETT, D.; STOREY, B.; COOK, Y.; MEDUNA, V. (Eds) Exploring the Last Continent. Springer International Publishing, 2015. 


\title{
Anexo I
}

\section{O que seus alunos já conhecem sobre as regiōes polares?}

E extremamente importante conhecer a realidade do conhecimento dos estudantes sobre a Antártica e Ártico. Sugerimos que os professores usem o questionário sugerido abaixo para conhecer o quanto os alunos sabem e definir que atividades serăo aplicadas em cada turma.

\begin{abstract}
Objetivo
Verificar o quanto os alunos conhecem sobre o Artico e a Antártica. Este exercicio irá permitir perceber/entender como os conceitos e opiniðes săo semelhantes ou diferentes entre os estudantes dos diversos niveis de ensino envolvidos. As questōes poderăo ser aplicadas por escola, por turma, por grupos, entre as turmas ou a título individual.

Sugere-se que os professores avaliem as questōes a serem apresentadas e, caso achem necessário reduzam ou ampliem o número de questôes de acordo com o grupo.
\end{abstract}

\section{Eaixa etária:}

\section{Mener que 6 anes}

Sugerir aos alunos que façam um desenho sobre como acham que são as regióes polares. Năo embasar o conhecimento dos alunos antes de solicitar, afinal o objetivo é avaliar o que eles sabem e comparar com o que eles irão saber depois das atividades realizadas.

\section{Entre 6 e 10 anes}

1. Qual das regióes polares fica mais próximo da sua casa/escola?

2. Como achas que săo estas regiōes?

3. Achas que existem seres vivos nestas regiőes? Quais?

4. Os ursos polares comem pinguins? Se năo, porquê?

5. Os ursos polares e os pinguins têm frio? Porquê??

6. Porque é que os ursos polares såo brancos?

7. Achas que as regióes polares são importantes para nós? Porquê?

8. Sabias que existem cientistas brasileiros que estudam estas regiōes? Já falaste com algum?

9. O que é que a tua escola/cidade/regiăo faz para ajudar o ambiente?

10. Os pés dos pinguins congelam? Se não, porquê?

11. Do que se alimentam as baleias?

12. Vocế acha que a poluição do seu país pode chegar até a Antártica e o Ártico?

\section{Entre 10 e 16 anes}

1. Qual das regióes polares fica mais próximo da tua casa/escola?

2. Estas regióes são importantes para o nosso planeta?

3. Que seres vivos habitam as regióes polares?

4. Quais as características destes seres vivos que permitem a sua sobrevivência?

5. Os ursos polares comem pinguins? Porquê?

6. Sabias que existem cientistas que estudam estas regiőes? Já falaste ou ouviste falar de algum?

7. Na tua escola as pessoas acreditam no aquecimento global?

8. Já debateste este assunto alguma vez?

9. O que é que a tua escola/cidade/região faz para ajudar o ambiente?

10. Quais as principais diferenças entre os polos norte e sul?

11. Você acredita que os poluentes emitidos no seu pais podem chegar aos polos? Porque?

12. Voce acha que attudes locais podem mudar o mundo no futuro?

\section{Acima de 16 anes}

Estes alunos podem escrever um texto sobre as regióes polares, estabelecer um limite de uma página sobre o que já sabem ou ouviram falar sobre as regióes polares. 
Após a avaliaçăo prévia sugerida no quadro acima os professores podem escolher entre as atividades sugeridas abaixo de maneira a contribuir para a formação dos estudantes e ampliar o conhecimento dos mesmos sobre os ambientes polares. Basta clicar no link para ser direcionado ao site/texto.

\section{Sugestões de vídeos, atividades e textos por faixa etária}

\section{Menores de 6 anos}

Video:

Ciência Hoje das Crianças - Pesquisa abaixo de zero graus

htto://www.youtube.com/watch?feature=player embedded\&v=DKd7PU3 AsE

\section{Sugestăo de Filme:}

Procurando Nemo

\section{Atividades:}

Jogo da Memória Antártico (INCT-APA)

http://www.biologia.ufri.brfinct-antartico/wp-content/uploads/2012/01/iogo-da-memoria.pdf Uma reuniăo de familia de pinguins httos://www.dropbox.com/s/vryopgkpu8s306m/AT1.pdf

A dieta dos ursos polares

http:/loinquinseskuas. webnode.com.brinews/a-dieta-dos-ursos-polares1/

Caça-palavras antártico

htto:lleinguinseskuas, webnede.com.brinewsica $\% c 3 \%$ a7a-2alavras $\% 20$ antartice\% 211

Livro de atividades Artico e Antártica

htto:ifiles.einguinseskuas, wobnode.com.bri200000975-226a623645/LivroAL.edf

\section{Entre 6 e 10 anos}

Textos:

Ciência Hoje das Crianças - Pesquisa abaixo de 0 graus

htte:lichc.cienciahojevelcom bripesquisa-abaixe-de-zere-graul

Como funcionam os pinguins?

http://ciencia.hsw.uol.com.bripinquim.htm

\section{Sugestăo de Filme:}

Procurando Nemo

\section{Atividades:}

Jogo da Memória Antártico (INCT-APA)

htto://www. biologia.ufri.brfinct-antartico/wp-content/uploads/2012/01/iogo-da-memoria.pdf Uma reuniăo de familia de pinguins

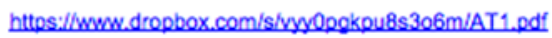




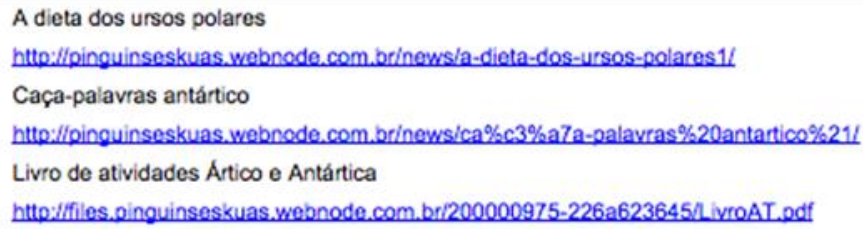

\section{Sugestăo de filme:}

A Marcha dos Pinguins

\section{Atividades:}

Projeto Transversal e Interdisciplinar: Inglês / Geografia / Regiōes Polares http:ilipinquinseskuas.webnode.com.brinewsiprojeto\%20transversal\%20e\%20interdisciplinar $\% 3$ a\%20ingl\%C3\%AAs $\% 20$ - $\% 20$ geografia $\% 20-\% 20$ reqi $\%$ C3\%B5es $\% 20$ polares $\% 20$ i Faça um modelo Terra-Mar htto:/foinquinseskuas.webnode.com.br/news/fa\%c3\%a7a $\% 20$ um $\% 20$ modelo $\% 20 \% 22$ terra $\% 20$ e\%20mar\%22\%20I

\section{Video:}

Estaçăo Antártica - reconstruçăo htto:/la1.globo.com/fantastico/noticia/2013/02/estacao-brasileira-na-antartica-que-fol-destruidaeer-incendie-esta-sende-reconstruida. $h$ tm

\section{Maiores de 16 anos}

Textos:

Substâncias tóxicas:

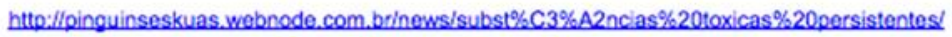
Informativos da APECS-Brasil - com diversos textos e informaçōes sobre as atividades de pesquisa e de Educaçăo e difusăo da ciência:

htte:/tumw. apecsbrasilcominformativel 
Derretimento dos polos influência o clima
htto:lijornalcidade vol.com. britioclaroldia-a-dia/verde-vida/92504-

Sugestăo de filme:

Uma verdade inconveniente

Atividades:

Projeto Transversal e Interdisciplinar: Inglês / Geografia / Regið̌es Polares

htto:/loinguinseskuas.webnode.com.brinews/projeto\% 20 transversal\% $200 \% 20$ interdisciplinar $\% 3$

a\%20 ing $\%$ C $3 \%$ AAs $\% 20$ - \%20geografia\%20-\%20regi\%C3\%B 3 es $\% 20$ olares $\% 20 /$

Faça um modelo Terra-Mar

htte:lfoinguinseskuas, webnode.com. brinews/fa $\% c 3 \% a 7 a \% 20$ um $\% 20$ modele $\% 20 \% 22$ terra $\% 20$

e\%20mar\% $22 \% 201$

\section{Videos:}

Band - Missăo Antártica:

Parte 1: http://www. voutube. com/watch?v=ZhExITSDA1A

Parte 2: http://www. voutube.com/watch?v=e4vc3Chi9.-0\&feature=relmfu

Fantástico, 2013:

http://g1.qlobo.com/fantastico/noticia/2013/02/estacao-brasileira-na-antartica-que-fol-destruidapor-incendio-esta-sendo-reconstruida.htm!

Globo Reporter, Antártica:

http: /fwnw. youtube.com/watch?v=SGOvgOpFazU

Brasil na Antartida: Estaçăo Comandante Ferraz - PROANTAR

htto://www.youtube.com/watch?v=gYSfo:XkFAo

Proposta de contato com cientistas:

\section{Palestras via Skype}

Serão organizadas palestras via Skype com pesquisadores do Brasil e do Exterior. Os professores devem manifestar interesse nestas atividades contatando a APECS-Brasil: apecsbrasil@gmail.com ou por meio dos pesquisadores com os quais já tem contato.

\section{Entrevistas}

Os professores podem manifestar interesse de seus alunos em realizar uma entrevista com pesquisadores do Brasil ou do exterior, via email ou Skype. Sugere-se que, após a palestra via Skype, o pesquisador seja contatado pelos alunos que podem enviar perguntas para eles.

Rev. Elet. Cient. UERGS, , v. 3, n. 2, p.340-371, 2017 


\section{Dando sequência a proposta...}

Com base na proposta de atividades, textos, videos apresentados acima, após os alunos terem desenvolvido alguns dos itens propostos, sugere-se a realização de atividades de fixaçăo $e$ integraçăo. As escolas podem escolher uma entre as atividades e integrar toda a escola durante a Semana Polar Internacional. Outras atividades podem ser sugeridas pelos professores e desenvolvidas, de acordo com a realidade de cada escola, em sua regiảo.

Desenvolvimento de atividades (4h) - Propōe-se que os alunos de turmas mais adiantadas desenvolvam, orientados pelos professores, atividades que possam ser aplicadas as turmas iniciais. Por exemplo, alunos de Ensino Fundamental podem utilizar as fotos para fazer um quebra-cabeças para os alunos de Ensino Primário. Alunos de Ensino Médio podem desenvolver um questionário orientado para ser aplicado aos alunos de Ensino Fundamental. Alunos das turmas finais do Ensino Médio podem preparar atividades para os alunos dos demais niveis de ensino. Todas as disciplinas podem ser integradas.

Produção de Tele-jornal (4h) - Por meio da pesquisa de textos de notícias veiculadas na mídia escrita os alunos individualmente ou em grupos săo convidados a preparar uma notícia em forma de tele-jornal. A apresentação pode ser feita para a turma ou para a escola em atividade conjunta (pesquisa + escolha da notícia $1 \mathrm{~h}$; elaboração do texto falado + treinamento $(1 \mathrm{~h})$; atividade aberta às demais turmas com apresentação do tele-jornal $(2 \mathrm{~h})$ ). Sugere-se que seja realizada gravaçăo/filmagem da atividade para usos em ocasiōes posteriores ou divulgação.

Produção de textos jornalísticos (4h) - Propõe-se que os alunos assistam notícias veiculadas na mídia falada e transformem em texto escrito treinando a habilidade da escrita. Os textos podem ser publicados no jornal da escola e as selecionadas pela escola podem ser enviados para publicação no Informativo Semestral da APECSBrasil. Os professores/educadores são convidados a enviar os textos de seus alunos para serem publicados no informativo da APECS-Brasil, por meio do e-mail apecsbrasil@gmail.com. 